\title{
A fatal case of Epstein-Barr virus infection with jaundice and renal failure
}

\author{
M. H. Davies \\ M.B., M.R.C.P. \\ B. PortMAnN \\ M.R.C.Path
}

\author{
P. Morgan-Capner $\dagger$ \\ B.Sc., M.B.
}
S. P. WILKINSON*
M.D., M.R.C.P.

\author{
R. Williams* \\ M.D., F.R.C.P. \\ The *Liver Unit, and †Department of Microbiology, King's College Hospital, \\ Denmark Hill, London SE5 9RS
}

\begin{abstract}
Summary
A fatal case of Epstein-Barr virus infection in a 17year-old male is described. The patient presented with an illness clinically typical of infectious mononucleosis but death followed development of renal failure, jaundice and pulmonary failure. There was no absolute lymphocytosis nor a significant number of atypical mononuclear cells in his peripheral blood. However, heterophile antibody and Epstein-Barr virus-specific IgM were present.
\end{abstract}

\section{Introduction}

A proliferation of T-lymphocytes, directed against virus-determined antigens on the surface of infected B-lymphocytes, is generally held to be responsible for the lymph-node hyperplasia, hepatosplenomegaly and typical blood picture which are found in infectious mononucleosis (Epstein and Achong, 1977). A fatal case of Epstein-Barr (EB) virus infection is described which was associated with jaundice and renal failure, but in which a significant atypical mononuclear cell response was not seen.

\section{Case report}

A previously healthy 17-year-old Caucasian male with no relevant family history, presented to his general practitioner with a 10-day history of lethargy, anorexia and sore throat. On examination, severe pharyngitis, palatal petechiae and mild cervical lymphadenopathy were noted. The total WCC was $2.4 \times 10^{9} / 1$ but a differential count was not obtained. The 'Monospot' test was positive. During the next 10 days he became increasingly unwell with deepening jaundice and then oliguria with upper gastrointestinal bleeding. $\mathrm{He}$ was

Requests for reprints: Dr P. Morgan-Capner, Department of Microbiology, King's College Hospital, Denmark Hill, London SE5 9RS. initially admitted to his local hospital and $24 \mathrm{hr}$ later transferred to King's College Hospital. Beforeo hospital admission he had received 4 days' treatment_with prednisone $20 \mathrm{mg} /$ day. Prednisone was dis- $Z$ continued on admission and he received no more? corticosteroids during his illness.

On admission, he was gravely ill with fever $\left(38.5^{\circ} \mathrm{C}\right)$, marked jaundice, and had moderafe hepatosplenomegaly. The maximal abnormalitese of the liver function tests were: serum bilirubin. $530 \mu \mathrm{mol} / \mathrm{l}$, alkaline phosphatase $385 \mathrm{i} . \mathrm{u} . / \mathrm{l}$, aspartate aminotransferase 300 i.u./l and prolongation of the prothrombin time $5 \mathrm{sec}$. Tests for hepatitis B surface antigen and antibody (by radioimmunoassay) and@ hepatitis A antibody (by immune electronmicro-市 scopy) were negative.

Oliguria continued with the plasma urea rising $\overline{\overline{0}}$ to $53.0 \mathrm{mmol} / 1$ and the creatinine to $555 \mu \mathrm{mol} / \mathrm{l}_{\Im}$ when continuous peritoneal dialysis was commenced The biochemical findings in the urine were in keeping with acute tubular necrosis (urine sodium 3 $68 \mathrm{mmol} / \mathrm{l}$, urine/plasma osmolality ratio $<1 \cdot 10$ ).

He developed clinical and radiological evidence of 3 pulmonary oedema, which became progressivelyo more severe, leading to a complete 'white-out' of the lung fields on chest X-ray and to severeo hypoxia $\left(\mathrm{PO}_{2} 6.0 \mathrm{kPa}\right)$. For this he required ventila-? tion which never adequately controlled the hypoxiao and the illness culminated in a series of hypoxic cardiac arrests 10 days after admission.

Findings relating to underlying $E B$ virus infection

The leucocyte count fluctuated between $5 \cdot 8$ and ${ }_{O}^{\omega}$ $11 \cdot 1 \times 10^{9} / 1$ but at no time was an absolute or relative lymphocytosis seen and atypical mononuclear cells? were never present in a concentration greater thanc $2 \%$ of the total leucocyte count. Cold agglutinins were present in the serum during the first few dayso 
after admission. The 'Monospot' test remained consistently positive as did the Paul-Bunnell test (320, before and after absorption with guinea-pig antigen; 10, after absorption with ox red cell antigen). IgG antibodies to EB virus capsid antigen were positive to a titre of 512 and specific IgM was found to be present after density gradient fractionation. The complement fixation titre against cytomegalovirus (CMV) was 8 and culture of the urine for CMV was negative.

\section{Post-mortem findings}

The liver was markedly enlarged (4000 g). Immediate post-mortem needle liver biopsy showed preservation of the normal architecture with minimal hepatic cell necrosis although ballooning of many hepatocytes was present (Fig. 1). A prominent cellular infiltrate consisting of both mononuclear and polymorphonuclear leucocytes was present within the portal tracts and dilated sinusoids, but no atypical cells were seen. Moderate splenomegaly $(750 \mathrm{~g})$ and cervical and mediastinal lymphadenopathy were also found at post-mortem although severe autolytic changes prevented accurate histological categorization of the cellular infiltrates seen in these tissues and the interpretation of electron microscopy sections. The lungs were congested with patchy haemorrhages, focal pneumonia and extensive non-aerated areas. Histology showed intraalveolar haemorrhages, fibrin, epithelial debris and a patchy, minimal infiltrate of mononuclear and polymorphonuclear leucocytes.

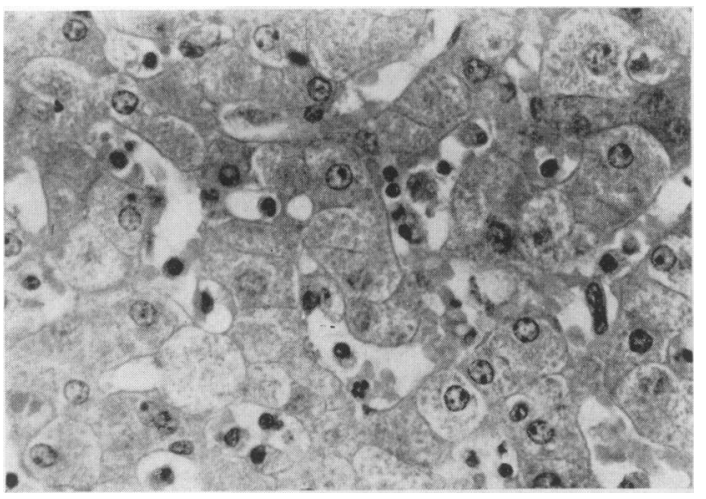

FIG. 1. Kupffer cell activation and prominent sinusoid mixed cell infiltrate in absence of significant liver cell damage $(\mathrm{HE}, \times 250)$.

\section{Discussion}

The virological studies in this case strongly suggest the cause of the illness to have been an EB virus infection. The factors that contributed to death were a combination of hepatic dysfunction, renal failure and severe pulmonary oedema. Minimal hepatic damage is common in infectious mononucleosis, although fatal hepatic necrosis is rare. In 2 of 3 previously reported cases of hepatic and renal failure associated with EB virus infection (Adkins and Steele, 1977; Chang and Campbell, 1975; Crawford et al., 1979) the degree of hepatic necrosis appears to have been more severe than in this case.

An unusual feature of the present case of EB virus infection was the absence of an absolute lymphocytosis or a significant number of atypical mononuclear cells. Smith and Denman (1978) suggest that a failure to develop atypical mononuclear cells during EB virus infection indicates a defect in cellmediated immunity. Unlike the case described by Smith and Denman, however, there was nothing in the medical history of this case to suggest a preexisting immune defect. Whether or not the administration of steroids early in his illness altered his cellmediated immune response is unknown. The importance of an impaired lymphocyte response in determining the outcome is also uncertain, although in one of the previously reported cases associated with hepatic and renal failure (Crawford et al., 1979) a deficiency of peripheral blood T-cells was found, but in the others (Adkins and Steele, 1977; Chang and Campbell, 1975) this was apparently normal as indicated by the appearance of numerous atypical mononuclear cells.

\section{Acknowledgments}

We wish to thank Dr Joan Edwards of the Central Public Health Laboratory, Colindale, London, for performing the EB serology.

\section{References}

Adkins, B.J. \& Steele, R.H. (1977) Death from massive hepatic necrosis in infectious mononucleosis. New Zealand Medical Journal, 85, 56.

Chang, M.Y. \& Campbell, W.G. (1975) Fatal infectious mononucleosis. Archives of Pathology, 99, 185.

Crawford, D.H., Epstein, M.A., Achong, B.G., Finerty, S., Newman, J., Liversedge, S., Tedder, R.S. \& Stewart, J.W. (1979) Virological and immunological studies on a fatal case of infectious mononucleosis. Journal of Infection, $1,37$.

Epstein, M.A. \& Achong, B.G. (1977) Pathogenesis of infectious mononucleosis. Lancet, ii, 1270.

Smith, H. \& Denman, A.M. (1978) A new manifestation of infection with Epstein-Barr virus. British Medical Journal, $2,248$. 